\title{
Impact of a Novel Bioabsorbable Implant on Radiation Treatment Planning for Breast Cancer
}

\author{
Roma Pradhan $^{1} \cdot$ Aromal Chekavar Suresh $^{2} \cdot$ Amit Agarwal $^{2}$
}

Published online: 30 January 2017

(c) Société Internationale de Chirurgie 2017

We read with interest the article "Impact of a Novel Bioabsorbable Implant on Radiation Treatment Planning for Breast Cancer" by Cross et al. [1]. We would like to congratulate the authors who made an effort to solve the problem related to tumor site marking in breast-conserving surgery. However, we have few queries about the study. We would like to know the time period of the study in which these 108 patients were included. Did all patients who underwent BCS during this time period marked with this 3D bioabsorbable implant? We would also like to know the follow-up of the patients, especially the 6-month and annual mammogram findings. The implant takes around 1 year for absorption, did it affect the mammographic picture done at 6 months? The implant was somewhat useful or not useful in $4.3 \%$ of patient despite their visibility. We would like to know the reason as to why it was not useful to the planning radiation oncologist.

\section{Reference}

1. Cross MJ, Lebovic GS, Ross J, Jones S, Smith A, Harms S (2016) Impact of a novel bioabsorbable implant on radiation treatment planning for breast cancer. World J Surg. doi:10.1007/s00268-0163711-y

Roma Pradhan

drromapradhan@yahoo.com

1 Endocrine and Breast Surgery, Sikkim Manipal Institute of Medical Sciences, Gangtok, India

2 Department of Endocrine Surgery, Sanjay Gandhi Post Graduate Institute of Medical Sciences, Lucknow, India 